\title{
Using Semi-Projective Doll Play Methods to Classify Middle Childhood Children Into Four Attachment Types: Types Associations With Distinctive Psychosocial Adaptation
}

\author{
David Granot ${ }^{1}$ \\ ${ }^{1}$ Spcial Education Department, Oranim the Academic College of Education, Tivon, Israel \\ Correspondence: David Granot, Special Education Department, Oranim Academic College, Tivon 36006, Israel. \\ Tel: 972-7-374-03678. E-mail: dudi_g@oranim.ac.il
}

Received: March 26, 2018 Accepted: April 16, 2018 Online Published: May 9, 2018

doi:10.5539/jedp.v8n2p1 URL: http://doi.org/10.5539/jedp.v8n2p1

\begin{abstract}
This research presents an adapted version of the Attachment Doll Story Completion Task for children in middle childhood (ADSCT for m-c), a measure for classifying children's representations of mother-child attachment relationships into four attachment types: secure, avoidant, ambivalent, and disorganized. The ADSCT enables interviewers to partially circumvent the sophistication and defensiveness of middle childhood children's story completions. A sample of 185 children in the 4th and 5th grades, and 50 mothers of children from one 4th and one 5 th grade class of that sample participated in the study. Children underwent the ADSCT for m-c procedure. Homeroom teachers, classmates, and the child reported on the children's psychosocial adaptation. A sub-sample of the mothers completed measures of maternal caring attitudes and practices. Associations between the different attachment types and distinct forms of adaptation showed that secure attachment exhibited positive social relationships and a low level of psychosocial and behavior problems; disorganized attachment showed the poorest adaptation, manifested in psychosocial problems, behavior problems, social problem, aggressiveness, and victimization. Avoidant attachment exhibited social problems, peer rejection, behavior problems, and compulsive thought. And ambivalent attachment showed social vulnerability, and intermediate level of adaptation, between the better functioning of the securely attached and the problematic functioning of the insecurely attached. Concurrent validity of the ADSCT for m-c with maternal attitudes and practices, and discriminate validity with reference to key cognitive variables were good.
\end{abstract}

Keywords: middle childhood, attachment representation, psychosocial adaptation, maternal secure base

\section{Introduction.}

A substantial number of studies have associated the child-parent attachment security of young children (1-6 years old) with psychosocial adaptation. Generally, the results showed that, when compared to insecurely attached children, securely attached children exhibited better psychosocial adaptation, manifested in a higher level of prosocial behavior, a lower level of anti-social behavior, and a lower level of behavior problems (Brumariu \& Kerns, 2010; Madigan, Atkinson, Laurin, \& Benoit, 2013; Marcus \& Kramer, 2001; Bureau \& Moss, 2010; Moss, Parent, Gosselin, Rousseau, \& St-Laurent 1996; Schneider, Atkinson, \& Tardif, 2001; Weinfield, Ogawa, \& Sroufe, 1997). An examination of the differences between the three insecure attachment patterns demonstrated that disorganized and avoidant children evinced the poorest psychosocial adaptation. This problematic adjustment was manifested in a low ability to conduct and maintain positive social relationships, as well as in hostility against peers (especially on the part of the disorganized children), and externalized and internalized behavior problems (Kerns \& Brumariu, 2014; Madigan, Brumariu; Villani, Atkinson, \& Lyons-Ruth, 2015; Bureau \& Moss, 2010; Brumariu \& Kerns, 2010: Moss et all., 1996; for a detailed review, see Seibert \& Kerns 2015). Finally, the ambivalent children showed difficulties in their relationships with peers (low sociometric status), and according to some reports, they displayed fearfulness in social situations, contributing to internalizing behavior problems (Brumariu \& Kerns, 2010; Bureau \& Moss, 2010; Cassidy \& Berlin, 1994; Berlin, Cassidy, \& Belsky, 1995; Madigan et al., 2013).

Middle childhood (8-12 years old) is a period of multiple cognitive and social changes that can influence the assessment of children's representations of attachment (Kerens, 2008). Children in middle childhood are more 
sophisticated, verbally fluent, and less intuitive, have better script knowledge (Flavell, Miller, \& Miller, 2002), and are more likely to mask emotions and deceive others (Saarni, Mumme, \& Campos, 1988) than are younger children. In the present study, an adaptation of the Attachment Doll Story Completion Task (ADSCT) is used to addresses these challenges. This tool enables interviewers to partially circumvent the sophistication and defensiveness of story completions by interviewees in middle childhood. ADSCT provides a reliable and valid measure that can classify 8- to 12-year-old children's representations of mother-child attachment relationships into four attachment types: secure, avoidant, ambivalent, and disorganized. The first objective of the present study is to improve our knowledge about whether the association between attachment and psychosocial adaptation in early childhood continues to hold true when attachment is evaluated in middle childhood, using semi-projective narrative techniques.

\subsection{Parent-Child Attachment Associations With Psychosocial Adaptation in Middle Childhood and Early Adolescence}

According to detailed reviews by both Kerns (2008) and Moss \& Lecompte (2015), concurrent and longitudinal studies conducted on middle childhood and early adolescent students have shown that schoolchildren whose relationships with their parents are characterized as secure rather than insecure attachment generally demonstrate better psychosocial adaptation, as manifested in the higher quality of these children's relationships with peers than of those with insecure attachment. Securely attached children were found to be better liked and less rejected by their peers, showed greater social cooperative engagement, formed more supportive friendships, and achieved higher peer popularity. Attachment security has also been linked to lower levels of externalizing and internalizing behavior problems (Kerns, 2008; Moss \& Lecompte 2015), and of antisocial/disruptive behavior (Scott, Briskman, Woolgar, Humayun, \& O'Connor, 2011). Moss \& Lecompte (2015) described the complex findings regarding the distinctive links between the different insecure attachment patterns (avoidant, ambivalent, and disorganized) on one hand, and externalized and internalized behavior problems on the other with respect to children in middle childhood.

At the same time, attachment researchers continued to reveal associations between the different patterns of insecure attachment and certain forms of problematic psychosocial adaptation and behavior in middle childhood and early adolescent samples. Fearon, Bakermans-Kranenburg, Van IJzendorn, Lapsly \& Roisman (2010) found robust correlations between disorganized attachment and externalizing problems, although the avoidant and the ambivalent children showed only somewhat higher levels of externalizing problems than did the secure children. Bureau and Moss (2010) found an association between disorganized attachment representations and frequent externalizing behavior problems. A meta-analysis by Madigan et al. (2015) showed that avoidant children did not appear to show a greater tendency toward externalizing problems than did secure children. In contrast to the results concerning externalizing problems, meta-analyses by Groh, Roisman, Van IJzendoorn, Bakermans-Kraneneburg \& Feron (2012) and by Madigan, Atkinson, Laurin \& Benoit (2012) revealed no substantial correlations between disorganization and total internalizing problems. Both meta-analyses, however, showed that avoidant children having an increased tendency toward internalizing problems. Furthermore, Bureau and Kerns (2010) found an association between ambivalent representations and some depression and anxiety responses in children, and a study by Madigan et al. (2015) reported that the association between ambivalent and internalizing behavior problems was greater than the one between avoidant and internalizing problems. By contrast, studies by Groh et al. (2012) and Madigan et al. (2012) showed that ambivalence was not substantially correlated with internalizing indicators.

Finally, research regarding the correlations between the insecure attachment patterns and distinct psychosocial behavior problems focused on comprehensive indicators of externalizing or internalizing behaviors (Seibert \& Kerns, 2015). In a longitudinal study, Seibert \& Kerns (2015) examined how the insecure patterns predict later socioemotional characteristics such as prosocial behavior, peer exclusion, anti-social behavior, peer victimization, relational aggression, and more. Their finding showed that disorganized children have the most problematic social interactions, reflected in low prosocial behavior, higher level of relational aggression, anti-social behavior, and the highest level of peer victimization. Avoidant children were rated high on anti-social behavior and were less liked by peers, but exhibited the lowest relational aggression. In contrast to previous research findings, the ambivalent group did not vary from the secure group on most peer interaction indices

Based on the above review, the second objective of the present study was to describe empirically the problematic psychosocial functioning of each of the three insecure attachment types (avoidant, ambivalent, and disorganized) in middle childhood. 


\subsection{Assessing Attachment in Middle Childhood}

There is presently no agreed-upon theory or procedure for assessing attachment in middle childhood, but a variety of methods and indices have been used (for a detailed review, see Madigan et al. 2015). According to Kerns (2008), researchers have adapted two main conceptualizations to measure attachment in middle childhood. One was to use measures and approaches first developed for early childhood, such as the projective doll play method (Jacobsen, Edelstein, \& Hofmann, 1994; Granot \& Mayseless, 2001), analysis of family drawings (Fury, Carlson, \& Sroufe, 1997), and behavioral observation of secure base reactions (Easterbrooks, Davidson, \& Chazan, 1993). The other was to adapt measures and approaches first used in adolescence, such as questionnaires that assess perceived attachment quality (Kerns, Klepac, \& Cole, 1996; Finnegan, Hodges, \& Perry, 1996; Kerns, Aspelmeier, Gentzler, $\&$ Grabill, 2001), and measures designed to assess the child's state of mind with regard to attachment (Ammaniti, van IJzendoorn, Speranza, \& Tambelli, 2000; Target, Ponagy, \& Shmueli-Goetz, 2003). Dwyer (2005) raised a concern that only a few researchers have examined the discriminant validity of the middle childhood different methods and indices, therefore further research is needed to examine the discriminant validity of middle childhood attachment measures (Kerns, 2008). With regard to measuring attachment, Bretherton (1985) advocated using its narrow rather than wide characterization, which would enable researchers to differentiate attachment from other features of the parent-child relationship. In other words, a measure of attachment based on the secure-base phenomenon appears closely related to the most common definitions of attachment (Bretherton, 1985). In the present study, the adaptation of the semi-projective doll play method is based on the narrow definition of attachment, distinguishing it from other aspects of the parent-child relationships by classifying the children into the four attachment types, mainly according to the secure-base concept.

\subsection{Semi-Projective Doll Play Techniques for Preschool Children}

Projective doll play techniques have been used to assess individual differences in attachment in several studies, with children between the ages 4-7 (for a review, see Solomon \& George, 2008, 400-402). The procedures generally included the enactment of story stems, with props and dolls, and a request that the child finish the story. The story stems included various attachment-related themes, such as hurt knee after falling, monster in the bedroom, and separation from mother for one night, with a reunion afterwards. Despite differences in protocol details, variations in approaches to classification and rating (see Solomon \& George, 2008), some common principles can be detected underlying the general indicators for classification of the children's narratives into four attachment types (Gloger-Tippelt, Gomille, Koenig, \& Vetter, 2002). In addition to developing classification indicators, researchers have examined the concurrent and predictive validity of early childhood doll play attachment classifications. Bretherton, Ridgeway, and Cassidy (1990) found significant associations between secure/insecure attachment representations in doll play and concurrent attachment classifications in reunion behaviors of 3.5-year-olds (Cassidy, 1988). Solomon, George, and De Jong (1995) found associations between the four attachment groups based on the doll play procedure and the pattern of attachment reunion behavior toward the mothers of 6-year-old children (Cassidy, 1988). Cassidy (1988) found predictive validity showing strong associations between doll play attachment classification and different measures of self-esteem. Finally, Goldwyn, Stanley, Smith, and Green (2000) found a clear association between 5-7 year-old children's doll play-based disorganized attachment classification and concurrent maternal Adult Attachment Interview-Unresolved (AAI-U) status, as well as teachers' rating of behavior problems. In all of these studies, the participants were children in their preschool years or early childhood, aged 4-7. The present study introduces an adaptation of the attachment doll story completion methodology to children in middle childhood and early adolescence (ADSCT for m-c).

\subsection{Semi-Projective Doll Play Techniques Attachment Classifications Concurrent Associations With Mother-Child Secure Base Relationship}

Waters and Cummings (2000) and Raikes and Thompson (2005) suggested an alternative approach to validating post-infancy attachment assessments, by establishing the contemporaneous associations with external measures of the parent-child relationship. They based their suggestion on Bowlby and Ainsworth's insights, according to which to be attached is to use the caregiver as a secure base from which to explore, and when necessary, as a haven of safety and a source of comfort. Waters and Cummings (2000) argued that assessing the use of the parent as a secure base, especially in challenging or difficult circumstances, is the gold standard, against which attachment measures must be validated for use with different age groups or different cultures. Consistent with this position, a study by Dubois-Comtois, Cyr \& Moss (2011) revealed concurrent associations between each of the four attachment groups classified using a doll-story representational measure and explicit characteristics of mother-school-child interaction qualities measured in an unstructured laboratory task (discussion of each other's affects, thoughts, and behavior). Moreover, Scott et al. (2011) revealed that secure attachment representation correlated with diverse 
features of concurrent parent-adolescent relations, such as higher parent positivity in the relationship, adequate monitoring, adequate disciplining, and lower level of poor parental monitoring of negative comments.

In the present study we focused on attachment to mother, who is considered the most significant attachment figure in nonclinical samples (O'Connor \& McCatrny, 2007). According to Cassidy (1994), negative emotion regulation is a central characteristic of mother-child attachment relationships. This argument is supported by Kerns (2008), who maintained that children who were securely attached to their mothers assimilated constructive ways of dealing with stress, and demonstrated greater resilience when coping with difficult situations, even in the absence of an attachment figure. Following this reasoning, the third objective of the present study was to validate the ADSCT for $\mathrm{m}-\mathrm{c}$ classifications against mothers' reports on their tendency to serve as a secure base for their children (Kerns et al., 1996), and on their coping with the child's negative emotions (Eisenberg, Fabes, \& Murphy, 1996). Mothers' reports referred to their willingness to serve as a secure base (be respectful and empathic, available and responsive, emotionally accessible etc.), and their tendency to provide assistance when the child was stressed or upset, tendency to provide affection and comfort, to contain, to address and encourage expression of negative emotions.

A number of studies (Cassidy, 1994; Crittenden, 1990; Crittenden, 2006; Feeney \& Noller, 1996; Lyons-Ruth, Bronfman, \& Atwood, 1999) suggest that each of the different attachment groups is characterized by a specific parenting profile. Based on these findings, we expected that, compared to mothers of insecure children, mothers of the secure type would report a significantly higher tendency to serve as a secure base for the child, and that in difficult circumstances these mothers would report a higher tendency to validate their children's negative emotional states, a higher tendency to respond with comforting behaviors when needed, and a higher ability to help children cope with their problems. We expected the mothers of the avoidant type to report the lowest level of comforting reactions to help their children feel better, a lower level of helping reactions when children were coping with problems that caused them to be distressed, and the highest level of tendency to minimize the seriousness of the situation. We expected the mothers of the ambivalent type to report diminished willingness to serve as an attachment figure, inconsistent caring responses in difficult circumstances, and a lower level of availability when their children needed help. Finally, we expected the mothers of the disorganized type to report the lowest tendency to serve as a secure base for their children, and the lowest tendency to validate their children's emotional states, and to report a higher tendency for parental distressful (helpless) reactions and the highest tendency for punitive (hostile) reactions when their children needed their help.

\subsection{Attachment Classifications Independent of Scholastic Cognitive Capacity}

Because telling stories (i.e., producing narratives) may be related to a child's expressive language proficiency, the present study examined the association between the four attachment types and these qualities. Because elementary school children's grades in math demonstrate a high correlation ( $\mathrm{r}=.6$ - .7) with I.Q. levels (McClelland, 1973), and I.Q. levels can be related also to the capacity to produce coherent narratives, the study also examined the association between the four attachment types and math proficiency.

\subsection{The Importance of the Appraiser of Psychosocial Adaptation}

According to a meta-analysis by Madigan et al. (2015), based on 165 studies of 3- to 18-year-old children, findings regarding the association between attachment and psychosocial problem behavior revealed the problem appraiser (i.e., parent, teacher, or child) to be a robust moderator of the effect size. Therefore, from a methodological standpoint, multiple appraisals are required (Madigan et al., 2015). Findings by Madigan et al. (2015) showed that studies where the informer regarding the problem behavior was the child exhibit larger effect size then studies that used parent or teacher reports of problem behavior. The present study used multiple psychosocial adaptation appraisals: about 13 same-sex classmate, the child, and the child's homeroom teachers. Based on the above findings of longitudinal and concurrent studies that linked the parent-child attachment of children aged 3-18 years with psychosocial adaptation, we hypothesized that:

H1. Children with secure attachment show a high level of prosocial behavior, and low levels of anti-social behavior, behavior problems (externalizing and internalizing), and of psychosocial problems.

H2. Children with disorganized attachment show a high level of anti-social behavior, especially aggressiveness (overt and covert), and the highest level of behavior problems (externalizing and internalizing) and peer victimization. Children with avoidant attachment show high levels of anti-social behavior, low levels of pro-social orientation, and intermediate levels of behavior problems (externalizing and internalizing) and of psychosocial difficulties. Children with ambivalent attachment show some difficulties integrating with their peer group, low levels of internalizing behavior problems, and an intermediate level of functioning in other peer relationships domain, between the adequate functioning of the secure group and the inadequate functioning of the disorganized 
and avoidant groups.

H3. Mothers in the secure attachment group show the highest tendency to serve as a secure figure, reflected in validating the children's negative emotions, comforting the children, and helping them cope with problems. Mothers in the avoidant attachment group show the lowest level of comforting and a low level of helping the children cope with problems. Mothers in the ambivalent attachment group show inconsistent caring responses, and a low level of availability and of helping children cope with problems. Mothers in the disorganized attachment group show the lowest tendency to serve as a secure figure, reflected in invalidating children's negative emotions, and a high tendency for distressful (helpless) and punitive (hostile) reactions.

\section{Method}

\subsection{Participants}

The children's sample (185) consisted, 107 in 4th grade and 78 in 5th grade, 97 boys and 88 girls. Mean class size was 26.5 students. Mean age was 10.35 years (range $=9.00-11.7$ ). The sample was recruited from two elementary schools that serve a typical middle-class suburban area in Israel. All 4th and 5th grade classes in the two schools were sampled. Parental permission was obtained for participation; compliance rate was $90 \%$.

\subsection{Procedure}

The research was conducted in three phases during one school year, with a fourth phase during the subsequent summer vacation. The first three phases of the study were part of a larger project researching the concurrent associations between middle childhood representations of mother-child attachment relationships, and how children in this age group process social information about their peer relationships (Granot \& Mayseless, 2012). The fourth phase consisted of a subsample of the mothers, examining their attitudes and practices as attachment figures. In phase 1, during the first trimester of the school year, children were escorted from their homeroom to an adjacent, quiet room where they were administered the ADSCT for m-c (Granot \& Mayseless, 2001). The procedure was videotaped. Two and a half months later, in phase 2, children were escorted once again to a quiet room and individually completed a background questionnaire and two self-report measures of attachment: The Attachment Security Scale (ASS) (Kerns et al., 1996), and the Preoccupied and Avoidant Coping Strategies Questionnaire (Finnegan, Hodges, \& Perry, 1996). Four months later, in phase 3, psychosocial adaptation to the school was examined across several dimensions using three sources of information, the homeroom teachers, the child, and the children's peers. The children's homeroom teachers completed the Teacher's Report Form (TRF) (Achenbach, 1991), the Social Competence Inventory (Rydell, Hagekull, \& Bohlin, 1997), and the Relational Aggression Scale (Crick, 1996). Each participating class underwent a sociometric procedure (Asher \& Dodge, 1986), and each child reported on same-sex classmates' psychosocial adaptation, using the Peer Nomination Inventory (Finnegan et al., 1996), finally, each child completed the Self-Report Inventory (SRI) on social characteristics (Granot, 2002). The northern district of the Israel Ministry of Education administered standardized regional reading comprehension, written expression, and math proficiency tests five times during that school year (September to June) at all the elementary schools in the region. At the end of the year, the schools calculated a standardized score for each child by averaging the five test scores in each subject. For the present study, at the end of the school year, we extracted from school records these standardized scores for all the children who participated in the study. In phase 4, during the summer vacation, an experienced interviewer contacted the 57 mothers of all the children in one 4 th grade and one 5 th grade class of the above sample. Compliance for this subsample was high, and 50 of the 57 mothers (88\%) agreed to participate in this part of the study. In a 1-hour home visit, mothers completed the Willingness to serve as an Attachment Figure (Kerns, Tomich, Aspelmeier, \& Contreras, 2000) and the Coping with Children's Negative Emotions Scale (CCNES) (Eisenberg, Febes, \& Murphy, 1996) questionnaires.

\subsection{Measures}

\subsubsection{Attachment Measure}

The ADSCT for m-c (Granot \& Mayseless, 2001) assesses the child's representations of attachment to the parent with respect to security, avoidance, ambivalence, and disorganization. The measure is an adaptation of Bretherton, Ridgeway, and Cassidy's (1990) story-stem technique, in which an interviewer begins to tell a story and the child uses dolls and props to complete it. The target child (the protagonist), one parent (in the present study, the mother), and siblings are introduced as characters in the story, but are assigned different names. Five stories that had been used with younger children (3-6-year-olds) were adapted to make stories appropriate for children 9-12 years of age. The themes of the stories were (a) spilled juice: while the family is seated at the dinner table, and the child accidentally spills juice on the floor; (b) hurt knee: the child tumbles off a high rock, hurting his or her knee, and it 
bleeds; (c) scary figure: the child is sent to bed and cries out that there is a scary figure in his or her bedroom; (d) departure story: the parent leaves for a 3-day trip and a babysitter stays with the children (older siblings are taken out); (e) reunion story: the babysitter sees the parent returns from the 3-day trip and announces the arrival to the children. The interviewer introduces each story with a short script and encourages the child to enact the story completion: "Show me what happened next." Open-ended questions and prompts are provided, when necessary, to encourage the child to play. The procedure, which takes about 45-60 minutes videotaped. Following extensive pretesting with 30 children, several modifications were made for middle childhood and early adolescence, including changes in the story content, in the administration procedure, and in the criteria for security, as well as a classification into four attachment types (for details, see the author 2012, p. 545-546).

We used a coding system for each story stem, and overall coding of the five stories to analyze and classify the child into one of four attachment types, analogously to the four attachment patterns. This was accomplished in two stages: (a) in the overall type rating, each participant was rated, on a 1-5 Likert scale, from 1=not typical at all to $5=$ very typical, for how characteristic his or her stories were of each of the four types; (b) in the type-based classification, the participant was assigned to one type. The descriptions of the four types cover four aspects: (a) emotional expression, (b) relationships with caregiver, (c) protagonist worldview, and (c) narrative structure. In the story completions, these aspects could be reflected in verbal and nonverbal (physical contact, moving away) communication between the protagonist and the caregiver figures. Delineation of the attachment types were based on the integration of three classification schemes developed by Cassidy (1988), Bretherton et al. (1990), and Solomon, George, and De Jong (1995). In utilizing the adaptation process, we developed a new coding and administration manuals and conducted a workshop procedure to achieve high interjudge agreement (all three apparatuses used in Kerns, Schlegelmich, Morgan, and Abraham (2005), see p. 64).

Children were classified into the secure type if the emotional expression of the child in the story was spontaneous and situation appropriate, the relationships with the caregiver was depicted as warm, accessible, stable, supporting, trusting, and mutual; if in the protagonist's worldview, threatening situations that might arise were resolved positively by the adult's responsible and reliable intervention and if the narrative structure of the story was diverse, logical, and integrated. Children were classified into the avoidant type if the emotional expression of the child in the story was shallow; if the relationships with the caregiver was characterized by distance, lack of emotional accessibility, diminished significance, and instrumental behavior; if the protagonist's worldview was characterized by a neutral attitude toward threatening situations, and by a perception that one must rely on oneself only and not expect help from others; and if the narrative structure of the story was minimalist, informative, and routine. Children were classified into the ambivalent type if the emotional expression of the child in the story was exaggerated, inappropriate, and inconsistent; if the relationship with the caregiver was characterized by lack of accessibility on his or her part, overdependence, and feelings of rejection, with the child blaming the caregiver; if according to the protagonist's worldview, coercive action was necessary to ensure appropriate caregiver action in threatening situations; and if the narrative structure of the story was somewhat diverse, open to unpredictable changes, and overloaded with irrelevant details that describe scenes not related to the situation. Children were classified into the disorganized type if the emotional expression of the child in the story was somewhat incoherent; if the relationship with the caregiver was characterized as unfit hierarchically; if the child appeared to be hostile, tending to control the adult, or helpless in relations with the caregiver; if in the protagonist's worldview, reality was frightening, and no one (including the caregiver and the protagonist) could be trusted because events were typically dangerous, and escape from danger only temporary; and if the narrative structure of the story was bizarre, frequently lacking in logical continuity and plausibility, and the overall atmosphere was chaotic.

Reliability and validity checks: ADSCT for m-c (Granot \& Mayseless, 2001) showed good interjudge agreement ( $80 \%$ category agreement, scale $r$ ranging from .78 to .85 ), and high test-retest reliability (94\%) over a 3-month interval in another Israeli sample including both genders. In the present study, two coders (D.G and I.K., who did not participate in the data collection phase), rated 52 interviews after evaluating 20 trial cases from a different sample. There was a good interjudge agreement between the two coders on classifications of the children into the four type-based groups in 50 of the 52 cases (kappa $=.92)$. The two remaining cases were resolved in a discussion between the coders. Both coders proceeded individually to rate the remaining videotapes (62 each), transferring them to the other rater whenever a classification was not unequivocal. Ten more cases were resolved in this manner. Interjudge reliability for the classification into attachment types was high ( $r$ ranged from .80 to .85).

Concurrent validity, associations with self-report measures of attachment: In another partial validation of the ADSCT for $\mathrm{m}$-c in the present study, attachment type rating was moderately associated, as expected, with self-report measures of attachment: ASS (Kerns et al., 1996) and the Preoccupied and Avoidant Coping Strategies Questionnaire (Finnegan et al., 1996). Based on previous studies, we expected only modest associations when 
different methods were used to assess attachment dimensions (Raikes \& Thompson, 2005; Van IJzendoorn, Vereijken, Bakermans, \& Riksen, 2004). Self-report on security of attachment was positively associated $(r=.23 ; p$ $<.001)$ with the rating of the secure type and negatively associated $(r=-.27 ; p<.001)$ with the rating of the avoidant type, and negatively but only marginally significantly associated $(r=-.13 ; p<.06)$ with the rating of the disorganized type. Self-report of avoidant coping strategies was positively associated $(r=.24 ; p<.01)$ with the rating of the avoidant type. Self-report of preoccupied coping strategies was positively but only marginally significantly associated $(r=.13 ; p<.06)$ with the rating of the ambivalent type.

\subsubsection{Psychosocial Adaptation Measures}

The Teacher's Report Form (TRF; Achenbach, 1991), the teacher's version of the Child Behavior Checklist (CBCL), was completed by the children's homeroom teachers. This widely-used measure consists of 113 items describing behavioral problems associated with middle childhood. Each item is scored by the teacher to reflect occurrence, frequency, and severity of the problem $(0=$ not true, $1=$ sometime or somewhat true, $2=$ often and very true). In the present study, Cronbach's alpha coefficients for the subscales were good: externalizing .95, internalizing .83, social problems .86 , thought problems .76, and attention problems .92 .

The Social Competence Inventory (Rydell, Hagekull, \& Bohlin, 1997) was used to assess prosocial orientation (17 items) and social initiative (8 items). The items were rated on a 5-point scale ranging from 1=doesn't apply at all, to $5=$ applies very well to the child, with higher score indicating higher competence. In the present study, Cronbach's alpha was good: prosocial orientation .94, social initiative .87 .

The Relational Aggression Scale (Crick, 1996) consists of 7 items characteristic of covert aggression, such as "when this child is mad at a peer, he or she gets even by excluding the peer from his or her clique or peer group" (Crick, 1996). The items were rated on a 5-point scale ranging from $1=$ doesn't apply at all, to $5=$ applies very well to the child, with higher score indicating higher relational aggression. In the present study, Cronbach's alpha of the scale was good: .93 .

The sociometric procedure (Asher \& Dodge, 1986), was used to collect sociometric information about the children. Each child was asked to nominate three classmates (of the same sex) he or she wanted to be good friends with, and to nominate three classmates (of the same sex) he or she did not want to be friends with. In the present study, two sociometric indices were calculated for each child: a positive and a negative nomination score. The scores were standardized within each class for same-sex groups.

The Peer Nomination Inventory (PNI) (Finnegan, Hodges, \& Perry, 1996) was used to identify various psychosocial adaptation dimensions. For each same-sex classmate on each of the 32 items, children rated their peers on a 3-point scale, ranging from 1=not characteristic of (name's) behavior, to $3=$ very characteristic of (name's) behavior. Scores were standardized within each class for same-sex groups. In the present study, measure yields four empirically derived factor subscales. Cronbach's alpha coefficients of the subscales were adequate: externalizing behavior problems .93 , internalizing behavior problems .77, prosocial behavior .70, and immature behavior .71 .

The Self-Report Inventory (SRI) of social characteristics (Granot, 2002) was used to measure three main social features: aggressiveness, victimization by peers, and prosocial behavior. The SRI is based on nine items from Finnegan, Hodges, and Perry's (1996) Peer Nomination Inventory (PNI), adapted to three self-report scales (worded in the first person). Each scale was comprised of three 4-point occurrence/frequency items ( $1=$ not at all, $2=$ seldom, $3=$ frequently, and $4=$ always). Cronbach's alpha coefficients of the scales were good for all three scales: aggressiveness .67, victim of peers .69, and prosocial behavior .70.

\subsubsection{Mother's Reports}

Willingness to serve as a secure base attachment figure (Kerns et al., 2000) was based on Block's (1965) Child Rearing Practices Report (CRPR). Ten of the items from Block's CRPR were chosen by Kerns et al. (1996) as indicators of the parent's acceptance of serving as an attachment figure for the target child and willingness to do so. The items reflect the assumption that parents of a securely attached child generally show a respectful and empathic attitude toward the child, are behaviorally available and responsive, and are emotionally accessible to the children at times of distress, (sample item: "I feel a child should be given comfort and understanding when he/she is scared or upset"). The ten CRPR item scores were transformed into a 7-point scale instead of Q-sorting the items. Kerns et al. (1996) reported a Cronbach's alpha of .73 for the scale. In the present study, Cronbach's alpha was .72.

Coping with Children's Negative Emotions Scale (CCNES; Eisenberg, Febes, \& Murphy, 1996) was used to assess mother's reactions to their children's negative emotions. Mothers were presented with 12 situations in which children are likely to experience distress and negative affect (e.g., weeping and being scared before injections; 
being frightened and unable to fall asleep after a scary TV program; being nervous about possibly embarrassing themselves in public). For each situation, mothers indicated (on a 7-point scale, ranging from 1=very unlikely to $7=$ very likely) how likely they would be to react in each of six different alternative ways: (a) parental distress reactions; (b) punitive responses; (c) encourage expression of emotion; (d) emotion-focused socialization reactions (comforting); (e) problem-focused socialization reactions; and (f) minimizing response. Eisenberg et al. (1996) reported adequate Cronbach's alpha coefficients, ranging from .70 to .88. In the present study, Cronbach's alpha coefficients were also adequate, ranging from .62 to .87 .

Children's background questionnaire. The children completed a children's background questionnaire concerning the parents' education and ethnic origin, number of rooms in the children's home, and number of people in the household. These indicators are accepted in Israel as good indices of socioeconomic status (SES; Yair, 1991). Three SES indicators were used: (a) parent's education, (b) ethnic origin, and (c) the ratio of people to rooms in the child's home. A higher level of education, Western ethnic origin, and a low ratio of people to rooms are considered indicative of higher levels of socioeconomic status (Yair, 1991).

Israeli Ministry of Education language and math tests. The normative, standardized, and regional tests of the Israeli Ministry of Education were used to assess the children's reading comprehension, written expression, and math proficiency. Scores were obtained from the school's records at the end of the school year. The scores reflect the children's abilities throughout the school year, and represent the mean of five tests administered in each subject during the year. Expressive language skills may affect storytelling, and expressive language skills and math proficiency are considered to reflect scholastic cognitive ability, which may affect the assessment of attachment representations (Parke \& O'Neil, 1999). Collecting this information enabled us to statistically control for this possible bias.

\section{Results}

\subsection{Preliminary Analyses}

The distribution of attachment types was as follows: $66.5 \%(n=123)$ of the children were classified as secure, $14.1 \%$ $(n=26)$ as avoidant, $9.2 \%(n=17)$ as ambivalent, and $10.3 \%(n=19)$ as disorganized. There was no significant difference between children classified as secure, avoidant, ambivalent or disorganized with regard to age and socioeconomic indicators. There was no significant difference between the four attachment type groups with regard to language skills (reading comprehension, written expression) or math proficiency. The effect of gender on secure classification was significant, $F(3,183)=4.35 ; p<.05$, with girls scoring a higher secure rating $(M=3.9$; $S D=1.2)$ than boys $(M=3.5 ; S D=1.2)$ (effect size $\eta^{2}=.02$ ). The gender effect was also significant for the avoidant classification, $F(3,183)=9.33 ; p<.01$, with boys scoring a higher avoidance rating $(M=2.0 ; \mathrm{SD}=1.2)$ than girls $(M=1.5 ; \mathrm{SD}=.9)$ (effect size $\left.\eta^{2}=.05\right)$. According to Del Giudice and Belsky (2010), hormonally determined reorganization of attachment that emerges in middle childhood generates sex differences in attachment patterns, with boys leaning toward higher avoidance and girls tending to exhibit higher "clinginess," and preoccupied behavior. Therefore, the above distribution was expected, and we statistically controlled for the effect of gender when using secure and avoidant attachment ratings.

\subsection{Associations Between ADSCT for m-c and Psychosocial Adaptation}

We performed four multivariate analyses of variance (MANOVAs), with gender and the four attachment types serving as predictor variables, and the four groups of psychosocial adaptation indices as criterion variables. Significant MANOVAs were followed up by ANOVAs, and when applicable, by post hoc tests (Duncan, $p<.05$ ) (See Table 1). In all these analyses, the interaction between gender and attachment group was not significant. 
Table 1. Measures of Psychosocial Adaptation to School as a Function of Attachment Groups

\begin{tabular}{|c|c|c|c|c|c|c|c|c|c|c|}
\hline \multirow{3}{*}{$\begin{array}{l}\text { Psychosocial } \\
\text { Adaptation }\end{array}$} & \multicolumn{10}{|c|}{ Type-based Classification of Attachment Representations } \\
\hline & \multicolumn{2}{|c|}{$\begin{array}{l}\text { Secure } \\
(n=123)\end{array}$} & \multicolumn{2}{|c|}{$\begin{array}{l}\text { Avoidant } \\
(n=26)\end{array}$} & \multicolumn{2}{|c|}{$\begin{array}{r}\text { Ambivalent } \\
(\mathrm{n}=17)\end{array}$} & \multicolumn{2}{|c|}{$\begin{array}{l}\text { Disorganized } \\
\qquad(\mathrm{n}=19)\end{array}$} & \multirow[t]{2}{*}{$\begin{array}{l}\text { F Value } \\
(3,177)\end{array}$} & \multirow[t]{2}{*}{$\eta^{2}$} \\
\hline & Mean & SD & Mean & SD & Mean & SD & Mean & SD & & \\
\hline \multicolumn{11}{|l|}{ Teachers' report: TRF } \\
\hline Externalizing & $1.11^{\mathrm{b}}$ & $(.2)$ & $1.36^{\mathrm{a}}$ & $(.2)$ & $1.23^{\mathrm{ab}}$ & $(.2)$ & $1.35^{\mathrm{a}}$ & $(.4)$ & $5.7^{* *}$ & .09 \\
\hline Internalizing & $1.10^{\mathrm{b}}$ & $(.1)$ & $1.20^{\mathrm{a}}$ & $(.2)$ & $1.20^{\mathrm{a}}$ & $(.2)$ & $1.20^{\mathrm{a}}$ & $(.2)$ & $4.9 * * *$ & .08 \\
\hline Thought problems & $1.01^{\mathrm{b}}$ & $(.0)$ & $1.20^{\mathrm{a}}$ & (.3) & $1.01^{\mathrm{b}}$ & $(.2)$ & $1.10^{\mathrm{b}}$ & (.1) & $5.0 * *$ & .08 \\
\hline Social problems & $1.10^{\mathrm{b}}$ & $(.2)$ & $1.30^{\mathrm{a}}$ & $(.4)$ & $1.25^{\mathrm{a}}$ & $(.4)$ & $1.30^{\mathrm{a}}$ & (.3) & $6.1 * * *$ & .09 \\
\hline Attention problems & 1.25 & $(.3)$ & 1.54 & $(.5)$ & 1.30 & $(.3)$ & 1.40 & $(.4)$ & 1.9 & .03 \\
\hline \multicolumn{11}{|l|}{ Teachers' report: - } \\
\hline \multicolumn{11}{|l|}{ Social competence } \\
\hline Prosocial orientation & $3.76^{\mathrm{a}}$ & $(.8)$ & $3.24^{\mathrm{b}}$ & $(.7)$ & $3.34^{\mathrm{b}}$ & $(.9)$ & $3.27^{\mathrm{b}}$ & $(.8)$ & $3.9^{*}$ & .06 \\
\hline Social initiative & 3.68 & $(.9)$ & 3.19 & $(.7)$ & 3.69 & $(.8)$ & 3.69 & $(.9)$ & 2.4 & .04 \\
\hline Teachers' report: & $2.22^{\mathrm{b}}$ & (1) & $2.25^{\mathrm{b}}$ & (1) & $2.29^{\mathrm{b}}$ & (1) & $3.10^{\mathrm{a}}$ & (1) & $3.3^{*}$ & .05 \\
\hline \multicolumn{11}{|l|}{ Relational aggression } \\
\hline \multicolumn{11}{|l|}{ Sociometric procedure } \\
\hline Positive nominations & $0.18^{\mathrm{a}}$ & $(.9)$ & $-0.44^{\mathrm{b}}$ & $(.8)$ & $-0.38^{\mathrm{b}}$ & $(.9)$ & $-0.20^{\mathrm{ab}}$ & $(.9)$ & $5.5 * * *$ & .07 \\
\hline Negative nominations & $-0.20^{\mathrm{b}}$ & (.8) & $0.36^{\mathrm{a}}$ & (1) & $0.56^{\mathrm{a}}$ & (1) & $0.30^{\mathrm{a}}$ & (1) & $4.5 * * *$ & .07 \\
\hline \multicolumn{11}{|l|}{ Peer report (PNI) } \\
\hline Externalizing & $1.38^{\mathrm{b}}$ & $(.2)$ & $1.53^{\mathrm{a}}$ & $(.3)$ & $1.48^{\mathrm{ab}}$ & $(.2)$ & $1.60^{\mathrm{a}}$ & (.4) & $4.3^{* *}$ & .05 \\
\hline Internalizing & 1.40 & $(.2)$ & 1.46 & $(.2)$ & 1.51 & (.1) & 1.46 & $(.2)$ & 1.5 & .03 \\
\hline Immaturity & $1.35^{\mathrm{b}}$ & $(.2)$ & $1.46^{\mathrm{a}}$ & $(.2)$ & $1.45^{\mathrm{ab}}$ & (.3) & $1.54^{\mathrm{a}}$ & $(.3)$ & $4.9 * *$ & .07 \\
\hline Prosocial behavior & $2.10^{\mathrm{a}}$ & $(.2)$ & $1.90^{\mathrm{b}}$ & $(.3)$ & $1.99^{\mathrm{ab}}$ & $(.2)$ & $1.91^{\mathrm{b}}$ & (.3) & $5.0^{* *}$ & .06 \\
\hline \multicolumn{11}{|l|}{ Self-report (SRI) } \\
\hline Aggressiveness & $1.29^{\mathrm{b}}$ & $(.3)$ & $1.42^{\mathrm{ab}}$ & (.4) & $1.27^{\mathrm{b}}$ & $(.4)$ & $1.60^{\mathrm{a}}$ & $(.4)$ & $3.3^{*}$ & .05 \\
\hline Victim of peers & $1.80^{\mathrm{b}}$ & $(.6)$ & $1.81^{\mathrm{b}}$ & (.6) & $2.04^{\mathrm{ab}}$ & $(.7)$ & $2.20^{\mathrm{a}}$ & $(.7)$ & $3.1^{*}$ & .06 \\
\hline Prosocial behavior & $3.53^{\mathrm{a}}$ & $(.4)$ & $3.13^{\mathrm{b}}$ & $(.5)$ & $3.53^{\mathrm{a}}$ & $(.4)$ & $3.35^{\mathrm{ab}}$ & $(.5)$ & $4.1 *$ & .07 \\
\hline
\end{tabular}

Note. Means in the same row that do not share the same superscript are significantly different (Duncan, $\mathrm{p}<.05) .{ }^{*} \mathrm{p}<.05 ;{ }^{* *}$ $\mathrm{p}<.01 ; * * * \mathrm{p}<.001$.

One MANOVA, with the eight scales of teachers' reports on psychosocial adaptation, was significant for the attachment variable (Wilks lambda $=.73, F(24,490)=2.4, p<.000$, Effect size $\eta^{2}=.07$ ), and for the gender variable (Wilks lambda=.85, F $(8,169)=3.6, p<.001$, Effect size $\eta^{2}=.10$ ). In follow-up ANOVAs, gender effects proved significant only for externalizing behavior problems $\left(\mathrm{F}(1,176)=11.4 ; p<.001\right.$, Effect size $\left.\eta^{2}=.06\right)$, as expected (Crick, 1996), with boys exhibiting higher level of externalizing problems $(M=1.25, S d=.34)$ than girls $(M=1.1$, $S d=.15$ ). An additional MANOVA, which used the four indices of peer reports (same-sex classmates) concerning the children's psychosocial adaptation was significant for the attachment variable (Wilks lambda $=.85, F(15,477)$ $=1.90 ; p<.02, \eta^{2}=.05$ ), but not for gender. The ANOVAs of peer reports on internalizing behavior problems were not significant. One additional MANOVA, which used the three indices of self-reports about the children's psychosocial adaptation was significant for the attachment variable (Wilks lambda $=.85, F(9,426)=3.38 ; p<.02$, $\eta^{2}=.06$ ) and for the gender variable (Wilks lambda $=.9, \mathrm{~F}(3,175)=3.8, p<.05$, Effect size $\eta^{2}=.06$ ). In follow-up ANOVAs, gender effects proved significant only for aggressiveness $\left(\mathrm{F}(1,177)=9.3 ; p<.003\right.$, Effect size $\left.\eta^{2}=.05\right)$, as expected (Crick, 1996), with boys exhibiting higher level of aggressiveness $(M=1.46, S d=.39)$ than girls $(M=$ 
$1.21, S d=.29)$. Post hoc tests for teachers' reports, peer reports, and self-report revealed that the secure attachment group exhibited the highest level of prosocial behaviors, and the lowest level of anti-social and psychosocial difficulties. The disorganized attachment group exhibited the lowest level of prosocial behaviors, and the highest level of anti-social and psychosocial difficulties, showing a particularly high tendency toward aggressiveness. The avoidant attachment group exhibited high levels of behavior and social problems, low prosocial orientation, and a tendency toward compulsive thought problems. The ambivalent attachment group showed high internalizing problems, high peer rejection, and intermediate levels of psychosocial difficulties. No significant differences emerged between the attachment groups in teachers' reports concerning children's attention problems (Table 1).

Finally The MANOVA on the two peer-based sociometric indices was significant for the attachment variable (Wilks lambda $=.90, F(6,352)=3.4, p<.004, \eta^{2}=.05$ ) but not for gender. Post hoc tests showed that the secure group received the largest number of positive nominations and the smallest number of negative ones. Post hoc tests also indicated that the three insecure groups received a similar, proportionally small number of positive nominations, and a large number of negative nominations (see Table 1).

\subsection{Relations Between ADSCT for M-C Type Classification, Mother'S Reports on Attachment Behavior, and Coping With Their Children's Negative Emotions}

The associations between mothers reported attachment behavior, coping with their children's negative emotions, and the children's attachment type was examined for 50 mothers. Thirty were mothers of children classified as having secure attachment, and 20 were mothers of children classified into the insecure attachment types (two ambivalent, eight avoidant, and 10 disorganized). Because only two mothers had children classified as ambivalent, these two cases were excluded from further analyses.

A series of 2 (gender) $\times 3$ (mothers of children of different attachment groups) analyses of variance (ANOVAs) were conducted on the mother's seven reports on their attachment behavior and Coping with Children's Negative Emotions. None of the gender main effects and the interactions with attachment groups was significant.

Table 2. Willingness to serve as an attachment figure, and reported coping with their children's negative emotions (CCNES) as a function of attachment representations

\begin{tabular}{|c|c|c|c|c|c|c|c|c|}
\hline \multicolumn{9}{|c|}{ Type-based Classification of Attachment Representations } \\
\hline \multirow[t]{2}{*}{ Mothers' report measures } & \multicolumn{2}{|l|}{$\begin{array}{l}\text { Secure } \\
(\mathrm{n}=30)\end{array}$} & \multicolumn{2}{|c|}{$\begin{array}{l}\text { Avoidant } \\
(\mathrm{n}=8)\end{array}$} & \multicolumn{2}{|c|}{$\begin{array}{l}\text { Disorganized } \\
(\mathrm{n}=10)\end{array}$} & \multirow[t]{2}{*}{$\begin{array}{l}\text { F Value } \\
(2,47)\end{array}$} & \multirow[t]{2}{*}{$\overline{\eta^{2}}$} \\
\hline & Mean & SD & Mean & SD & Mean & SD & & \\
\hline $\begin{array}{l}\text { Willingness to serve as an } \\
\text { attachment figure }\end{array}$ & $6.09^{\mathrm{a}}$ & (.6) & $5.54^{\mathrm{ab}}$ & $(.8)$ & $5.41^{\mathrm{b}}$ & (1) & $3.98^{*}$ & .06 \\
\hline \multicolumn{9}{|l|}{$\begin{array}{l}\text { Mothers' reports on coping with } \\
\text { their children's negative } \\
\text { emotions }\end{array}$} \\
\hline Parental distress reactions & $2.63^{\mathrm{b}}$ & (.8) & $3.31^{\mathrm{ab}}$ & (1.3) & $3.25^{\mathrm{a}}$ & (.6) & $3.26^{*}$ & .07 \\
\hline Punitive responses & $2.04^{\mathrm{b}}$ & $(.8)$ & $2.13^{\mathrm{ab}}$ & (.9) & $2.83^{\mathrm{a}}$ & $(1.2)$ & $2.93^{*}$ & .07 \\
\hline $\begin{array}{l}\text { Encourage expression of emotion } \\
\text { (sensitive care) }\end{array}$ & $5.46^{\mathrm{a}}$ & $(.9)$ & $4.85^{\mathrm{ab}}$ & $(1.2)$ & $4.59^{\mathrm{b}}$ & (1.3) & $3.14^{*}$ & .08 \\
\hline $\begin{array}{l}\text { Emotion-focused socialization } \\
\text { reactions (comforting) }\end{array}$ & $5.76^{\mathrm{a}}$ & (.7) & $4.99^{\mathrm{b}}$ & (1.4) & $5.47^{\mathrm{ab}}$ & (.7) & $2.50^{*}$ & .08 \\
\hline $\begin{array}{l}\text { Problem-focused socialization } \\
\text { reactions (assisting in coping with } \\
\text { distress problems) }\end{array}$ & $6.10^{\mathrm{a}}$ & (.6) & $4.85^{\mathrm{b}}$ & $(1.8)$ & $5.48^{\mathrm{b}}$ & $(.5)$ & $6.93^{* * *}$ & .09 \\
\hline Minimizing response & 3.37 & (.8) & 3.10 & (1.3) & 3.64 & (1.6) & .50 & .06 \\
\hline
\end{tabular}

Note. Means in the same row that do not share the same superscript are significantly different (L.S.D, $\mathrm{p}<.05) . * \mathrm{p}<.05 ; * * *$ $\mathrm{p}<.001$.

Analyses revealed that the mothers of the secure type group rated significantly higher on willingness to serve as an 
attachment figure, on encouraging expression of emotion (sensitive care), on emotion-focused reactions (comforting), and on assisting the child in coping with distressing problems, and were significantly lower on parental distress and punitive reactions. Mothers of the avoidant type group rated significantly lower on emotion-focused reactions (comforting) and on assisting the child in coping with distressing problems. Mothers of the disorganized type group rated significantly higher on parental distress and punitive reactions, and significantly lower on willingness to serve as an attachment figure, on encouraging expression of emotion (sensitive care), and on assisting the child in coping with distressing problems. No significant differences between the mothers of the three attachment groups emerged with regard to minimizing response (see Table 2).

\section{Discussion}

The purpose of the present study was to answer three questions: (a) whether the association between secure attachment in early childhood and psychosocial adaptation continues in middle childhood (evaluated using representation techniques); (b) whether we can empirically portray the problematic psychosocial functioning of each of the three insecure attachment types (avoidant, ambivalent, and disorganized) in middle childhood; and (c) whether the ADSCT for the m-c prototype classification is concurrently associated with mothers' reports on mother-child interactions: their willingness to serve as a secure base figure and their coping with children's negative motions, and whether the ADSCT is independent of scholastic cognitive capacity (discriminate validity).

According to attachment theory, secure children, who are assumed to be raised by available, responsive, and sensitive parents, are expected to develop an open, flexible, and non-defensive social orientation, with a high tendency for prosocial behavior and cooperation with others, and a low tendency for anti-social and aggressive behavior toward others (Cassidy, 2008). Consistent with the above conceptualization, and confirming H1, results show that children classified as secure exhibited the lowest levels of behavior problems (internalizing, externalizing), psychosocial difficulties (thought problems, immaturity, and victimization by peers), social problems, and peer rejection, and the highest levels of prosocial behavior and peer popularity. Using multiple different psychosocial adaptation appraisals, the present study confirmed that the association between secure attachment (classified by behavioral observation measures) and better psychosocial adaptation revealed in early childhood persists when secure attachment is classified in middle childhood using the ADSCT for m-c.

$\mathrm{H} 2$ concerns the definition of distinct forms of problematic psychosocial adaptation for each of the three insecure attachment types (avoidant, ambivalent, and disorganized) in middle childhood. The disorganized pattern is rooted in an improper parent-child hierarchy, in which the parent's behaviors (frightening or frightened) prevent reciprocity in the relationship and encourage the child to perceive the world as an intimidating place (Seibert \& Kerns, 2015), leaving the child with two conceivable alternatives: counteract: be hostile/aggressive or give up (be helpless). The improper hierarchy also prevents the child from acquiring effective emotion regulation skills (Lyons-Ruth, Bronfman, \& Atwood, 1999; Seibert \& Kerns 2015). Based on this experience, children with disorganized attachment are likely to develop either anti-social orientations, which involves hostility and aggressiveness, or helplessness, failing to associate with peers, which may cause them to be victimized by peers (Lyons-Ruth et al., 1999; Seibert \& Kerns 2015). Consistent with the above conceptualization, children classified as disorganized showed the poorest school adaptation, manifested in high levels of behavior problems (internalizing, externalizing), psychosocial difficulties (immaturity), social problems, peer rejection, and low levels of prosocial behavior and peer popularity. Finally, they were most conspicuous in their high aggressiveness (covert and overt) and victimhood. The children with avoidant attachment, who are assumed to be raised by a rejecting parent, are expected to develop strategies that minimize the expression of all types of social affect (Cassidy, 2008), and are therefore likely to develop a distancing social withdrawal behavior and chronic suspense about the availability of the attachment figure (Kerns \& Brumariu, 2014), without the ability to openly promote prosocial interactions with others, especially when feeling rejected (Cassidy, 2008), resulting in overt anti-social behavior (Finnegan et al., 1996), and in few close relationships with peers (Seibert \& Kerns, 2015). Consistent with the above conceptualization, children classified as avoidant showed behavior problems (internalizing, externalizing), psychosocial difficulties (immaturity), social problems, and peer rejection. These were most conspicuous in their lowest level of prosocial orientation and highest level of compulsive thought problems. The children with ambivalent attachment, who are considered to be raised by a typically inconsistent and unreliably responsive parent, developed a skeptical attitude and a desire to coerce the caregiver to respond to their needs (Cassidy, 2008), which can cause them to develop several tendencies: watchfulness about staying in the proximity of caregivers, and therefore poor preparedness to associate with their peers (Brumariu \& Kerns, 2008); a heightened emotion-regulation strategy, with elevated expressions of distress, or dependence (Cassidy, 2008), manifest in internalizing behavior problems and a tendency toward fear of negative evaluation by peers (Cassidy \& Berlin, 1994); a measure of passivity with peers, but sufficient preoccupation and compliance to escape problems 
(Seibert \& Kerns, 2015). Consistent with the above conceptualization, children classified in the present study as ambivalently attached, showed high levels of internalizing behavior problems and social problems (according to reports by homeroom teachers). According to the other informants (peers), however, their psychosocial difficulties, social problems, and aggressiveness were less problematic than those of the other categories of children with insecure attachment. They were also most conspicuous in their discrepancy between perceiving themselves as highly prosocial toward peers and experiencing high peer rejection.

Similarly to the research by Seibert \& Kerns (2015), in the present study, the group of children with ambivalent attachment, as expected, showed some internalizing problem behaviors and evidence of low sociometric status, but in other domains (externalized behavior, psychosocial difficulties, and prosocial attitude), their functioning was less problematic then that of the disorganized and the avoidant groups. According to Del Giudice and Belsky (2010), the transition from early to middle childhood is a phase influenced by hormonal changes, which redirects the preoccupied/ambivalent attachment strategy to adjusting behavioral areas such as aggressiveness, trust, cooperation, and other social domains. As a result, this passage can change the psychosocial functioning of the ambivalent types and make it better adapted to the school environment.

Concerning H3, Waters and Cummings (2000) described attachment in middle childhood as a "supervision partnership," in which children cooperate with parents to achieve goals of both exploration and security. According to Raikes and Thompson (2005), behaviors expected to be associated with attachment in middle childhood should include seeking parents' assistance when the child is stressed or upset, sharing affection with parents, disclosing information about important events in the child's life, and seeking help with school and social problems. Based on both claims, the present study assessed the relationships between mothers' reports on their attachment behavior and their children's classification into attachment types. Because only two children in the subsample of 50 used to examine the association between ADSCT for m-c classification and mother's reports were categorized as ambivalent, the characteristic reactions of their mothers could not be statistically examined.

According to $\mathrm{H} 3$, significant differences were found between mothers of children classified into the secure type and mothers of children classified into the insecure types (avoidant and disorganized) in their reported behaviors associated with attachment relationships with their children. The mothers of the secure children reported a significantly higher willingness to serve as an attachment figure for the child than did the mothers of the insecure children. Mothers of the secure children also reported the highest tendency to provide sensitive and responsive care for their children in difficult circumstances, validating their children's negative emotional states, comforting them when needed, and being capable to help the children cope with their problems. The associations between mothers' reported attachment behavior and their children's insecure classification (avoidant and disorganized) was consistent with previous theoretical and empirical studies (Crittenden, 2006; Feeney \& Noller, 1996; Lyons-Ruth, Bronfman, \& Atwood, 1999). Mothers of avoidant children reported the lowest levels of response with comforting strategies to help their children feel better in difficult circumstances, and reported a low tendency to use helping reactions when their children are coping with problems that cause them to express negative emotions. Finally, mothers of disorganized children reported the lowest willingness to serve as an attachment figure for the children, the lowest tendency to validate their children's emotional states, the highest parental distress reactions when their children needed their help or comforting, and the highest tendency to engage in punitive (hostile) reactions.

Discriminate validity. The four-type classification was found to be independent of scholastic cognitive capacity, including reading comprehension, written expression, and math proficiency, as well as of SES and age, demonstrating important indices discriminate validity.

\subsection{Conclusions and Limitations}

The present study enabled us to differentiate between distinct forms of problematic psychosocial adaptation for each of the three insecure attachment types in middle childhood. The study showed that the avoidant, ambivalent, and disorganized attachments resulted in different problematic social orientations, consistent with the distinct social orientations expected by attachment researchers with regard to children having these insecure attachment relationships with their parents. The findings revealed that the association between the insecure patterns and the typical problematic psychosocial adaptations that appeared in early childhood persist when the children are classified using the ADSCT for m-c in middle childhood, with ambivalent children showing better social functioning. Several limitations of this study invite additional research. First, the concurrent association may also be related to a third factor, such as the children's temperament, which affects both the children's and the mothers' perceptions. Second, the ADSCT shows only a moderate correlation with the self-report measures of attachment; further studies are needed to validate the children's ADSCT attachment types against measures that can assess their parents" "state of mind" toward attachment (AAI), using a sample that is large enough to include sufficient samples 
of the three insecure types. Third, our research focused on mother-child attachment representations. Relationships with fathers are another important context that affects psychosocial adaptation (Williams \& Kelly, 2005).

\section{References}

Achenbach, T. M. (1991). Manual for Teacher's Report Form. Burlington, VT: University of Vermont Department of Psychiatry.

Ammaniti, M., van IJzendorn, M. H., Speranza, A. M., \& Tambelli, R. (2000). Internal working models of attachment during late childhood and early adolescence: An exploration of stability and change. Attachment and human development, 2, 328-346. https://doi.org/10.1080/14616730010001587

Asher, S., \& Dodge, K.A. (1986). Identifying children who are rejected by their peers. Developmental Psychology, 22, 444-449. https://doi.org/10.1037/0012-1649.22.4.444

Berlin, L. J., Cassidy, J., \& Belsky, J. (1995). Loneliness in young children and infant-mother attachment: A longitudinal study. Merrill-Palmer Quarterly, 41, 91-103.

Block, J. H. (1965). The child-rearing practices report (CRPR): A set of $Q$ items for the description of parental socialization attitudes and values. University of California, Berkeley, Institute of Human Development.

Bretherton, I. (1985). Attachment theory: Retrospect and prospect. In I. Bretherton \& E Waters (Eds.), Growing points of attachment theory and research. Monographs of the Society for Research in Child Development, 50(1-2, Serial No. 209), 3-35. https://doi.org/10.2307/3333824

Bretherton, I., Ridgeway, D., \& Cassidy, J. (1990) Assessing internal working models of the attachment relationship: An attachment story completion task for 3-year-olds. In M. Greenberg, D. Cicchetti, \& E. M. Cummings (Eds.), Attachment in the preschool years; Theory, research, and intervention (pp. 273-308). Chicago: The University of Chicago Press.

Brumariu, L. E., \& Kerns, A. K. (2008). Mother-Child attachment and social anxiety symptoms in middle childhood. Journal of applied developmental psychology, 29(5), 393-402. https://doi.org/10.1016/j.appdev.2008.06.002

Brumariu, L. E., \& Kerns, A. K. (2010). Parent-child attachment and internalizing symptoms in childhood and adolescence: A review of empirical findings and future directions. Developmental and Psychopathology, 22, 177-203. https://doi.org/10.1017/S0954579409990344

Bureau, J-F., \& Moss, E. (2010). Behavioral precursors of attachment representations in middle childhood and links with child social adaptation. British Journal of Developmental Psychology, 28, 657-677. https://doi.org/10.1348/026151009X468062

Cassidy, J. (1988). Child-mother attachment and the self in six-year-olds. Child Development, 59, 121-134. https://doi.org/10.2307/1130394

Cassidy, J. (1994). Emotion regulation: Influences of attachment relationships. In N. A. Fox (Ed.), The development of emotion regulation, biological and behavioral considerations. Monographs of the Society for Research in Child Development, 59, (pp. 228-250) (2-3 Serial No 240).

Cassidy, J. (2008). The nature of the child's ties. In J. Cassidy \& P. R. Shaver (Eds.), Handbook of attachment: Theory, research and clinical applications (2nd ed., pp. 3-22). New York: Guilford Press.

Cassidy, J., \& Berlin, L. J. (1994). The insecure/ambivalent pattern of attachment: Theory and research. Child Development, 65, 971-991. https://doi.org/10.2307/1131298

Del Giudice, M., \& Belsky, J. (2010). Sex differences in attachment emerge in middle childhood: An evolutionary hypothesis. Child Development Perspective, 4(2), 97-105. https://doi.org/10.1111/j.1750-8606.2010.00125.x

Crick, N. R. (1996). The role of overt aggression, relational aggression, and prosocial behavior in the prediction of children's future social adjustment. Child Development, 67, 2317-2327. https://doi.org/10.2307/1131625

Crittenden, P. M. (1990). Internal representation models of attachment relationships. Infant Mental Health Journal, 11, 259-277. https://doi.org/10.1002/1097-0355(199023)11:3<259::AID-IMHJ2280110308>3.0.CO;2-J

Crittenden, P. M. (2006). A dynamic-maturational model of attachment. Australian and New Zealand Journal of Family Therapy, 27, 105-115. https://doi.org/10.1002/j.1467-8438.2006.tb00704.x

Dubois-Comtois, K., Cyr. C., \& Moss, E. (2011). Attachment behavior and mother-child conversations as predictors of attachment representations in middle childhood: A longitudinal study. Attachment \& Human 
Development, 13(4), 335-357. https://doi.org/10.1080/14616734.2011.584455

Dwyer, K. M. (2005). The meaning and measurement of attachment in middle and late childhood. Human Development, 48, 155-182. https://doi.org/10.1159/000085519

Easerbrooks, M. A., Davidson, C. E., \& Chazan, R. (1993). Psychosocial risk, attachment, and behavior problems among school-aged children. Development and Psychopathology, 5, 389-402. https://doi.org/10.1017/S095457940000448X

Eisenberg N., Fabes, R. A., \& Murphy, B. C. (1996). Parents' Reactions to Children's Negative Emotions: Relations to Children's Social Competence and comforting behavior. Child Development, 67, 2227-2247. https://doi.org/10.2307/1131620

Fearon, R.P., Bakermans-Kranenburg, M. J., Van Ijzendorn, M. H., Lapsley, A.-M., \& Roisman, G. I. (2010). The significance of insecure attachment and disorganization in the development of children's externalizing behavior: A meta-analytic study. Child Development, 81, 435-456. https://doi.org/10.1111/j.1467-8624.2009.01405.x

Feeney, N., \& Noller, P. (1996). Adult attachment, Sage Publications. https://doi.org/10.4135/9781452243276

Finnegan, R.A., Hodges, E., \& Perry, D.G. (1996). Preoccupied and Avoidant coping during middle childhood. Child Development, 67, 1318-1328. https://doi.org/10.2307/1131702

Flavell, J. H., Miller, P. H., \& Miller, S. A. (2002). Cognitive development (4th ed). Upper Saddle River, NJ: Prentice Hall.

Fury, G., Carlson, E., \& Sroufe, L. A. (1997). Children's representations of attachment relationships in family drawings. Child Development, 68, 1154-1164. https://doi.org/10.2307/1132298

Goldwyn, R., Stanlet, C., Smith, V., \& Green, J. (2000). The Manchester child attachment story task: Relationship with parental AAI, SAT and child behavior. Attachment \& Human Development, 2, 71-84. https://doi.org/10.1080/146167300361327

Gloger-Tippelt, G., Gomille, B., Koenig, L., \& Vetter, J. (2002). Attachment representations in 6-year-olds: Related longitudinally to the quality of attachment in infancy and mother's attachment representations. Attachment \& Human Development, 4(3), 318-339. https://doi.org/10.1080/14616730210167221

Granot, D., \& Mayseless, O. (2001). Attachment security and adjustment to school in middle childhood. International journal of behavioral development, 25(6), 530-541

Granot, D. (2002). Social Information processing as a mediator of the associations between children's representation of attachment relationships and socioemotional adjustment. (Doctoral thesis, Faculty of education, Department of Education, University Haifa). Haifa Israel.

Granot, D., \& Mayseless, O. (2012). Representations of mother-child attachment relationships and social-information processing of peer relationships in early adolescence. Journal of Early Adolescence, 32(4) 537-564.

Groh, A. M., Roisman, G. I., Van Ijzendoren, M. H., Bakermans-Kranenburg, M. J., \& Fearon, R. P. (2012). The significance of disorganized attachment for children's internalizing symptoms: A meta-analytic study. Child Development, 83, 591-610.

Jacobsen, T., Edelstein, W., \& Hofmann, V. (1994). A longitudinal study of the relation between representations of attachment in childhood and cognitive functioning in childhood and adolescence. Developmental Psychology, 30, 112-124. https://doi.org/10.1037/0012-1649.30.1.112

Krller, H. (2013). Attachment and culture. Cross-cultural psychology, 44(2), 175-195. https://doi.org/10.1177/0022022112472253

Kerns, K. A. (2008). Attachment in middle childhood. In J. Cassidy \& P. R. Shaver (Eds.), Handbook of attachment: Theory, research, and clinical applications (pp. 366-382). New York: Guilford.

Kerns, K.A., Aspelmeier, J. E., Gentzler, A. L., \& Grabill, C. (2001). Parent-child attachment and monitoring in middle childhood. Journal of family psychology, 15, 69-81. https://doi.org/10.1037/0893-3200.15.1.69

Kerns, K.A., \& Brumariu, L. E. (2014). Is insecure parent-child attachment a risk factor for the development of anxiety in childhood or adolescence? Child Development perspective, 8(1), 12-17. https://doi.org/10.1111/cdep.12054 
Kerns, K.A., Klepac, L., \& Cole, A. (1996). Peer relationships and preadolescents' perceptions of security in the $\begin{array}{llll}\text { child-mother } \quad \text { relationship. } & \text { Developmental }\end{array}$ https://doi.org/10.1037/0012-1649.32.3.457

Kerns, K. A., Tomich, P. L., Aspelmeier, J. E. \& Contreras, J. M. (2000). Attachment-Based assessments of parent-child relationships in middle childhood. Developmental Psychology, 36, 614-626. https://doi.org/10.1037/0012-1649.36.5.614

Kerns, K. A., Schlegelmich, A., Morgan, T. A., \& Abraham, M. M. (2005). Assessing attachment in middle childhood. In K.A. Kerns \& R.A. Richardson (Eds.), Attachment in middle childhood (pp 46-70), Guilford, N.Y.

Lyons-Ruth, K., Bronfman, E., \& Atwood, G. (1999). A Relational diathesis model of hostile-helpless states of mind. In J. Solomon \& C. George (Eds.), Attachment Disorganization (pp. 33-69). The Guilford Publications.

Madigan, S., Atkinson, L., Laurin, K., \& Benoit, D. (2012). Attachment and internalizing behavior in early childhood: A meta-analysis. Developmental Psychology, 49, 1-18.

Madigan, S., Atkinson, L., Laurin, K., \& Benoit, D. (2013) Attachment and internalizing behavior in childhood: A meta-analysis. Developmental Psychology, 49. 672-689. https://doi.org/10.1037/a0028793

Madigan, S., Brumariu, L, Villani, V., Atkinson, L, \& Lyons_Ruth, K. (2015). Representational and questionnaire measures of attachment: A meta-analysis of relations to child internalizing and externalizing problems. Psychological Bulletin, 142, 1-33.

Marcus, R. F., \& Kramer, C. (2001). Reactive and proactive aggression: Attachment and social competence predictors. The Journal of Genetic Psychology, 162, 260-275. https://doi.org/10.1080/00221320109597483

McClelland, D. C. (1973). Testing for competence rather than for intelligence. American Psychologist, 28, 1-14. https://doi.org/10.1037/h0034092

Moss, E., \& Lecompte, V. (2015) Attachment and socioemotional problems in meddle childhood. In G. Bosmans \& K. A. Kerns (Eds.), Attachment in middle childhood: Theoretical advance and new directions in an emerging field. New Directions for Child and Adolescent Development, 148, 63-76. https://doi.org/10.1002/cad.20095

Moss, E., Parent, S., Gosselin, C., Rousseau, D., \& St-Laurent, D. (1996). Attachment and teacher-reported behavior problems during the preschool and early school-age period. Development and Psychopathology, 8, 511-525. https://doi.org/10.1017/S0954579400007240

O'Connor, E., \& McCatrny K. (2007). Examining teacher-child relationships and achievement as a part of an ecological model of development. American Educational Research Journal, 44(2), 340-369. https://doi.org/10.3102/0002831207302172

Park, K. A., \& O'Neil, R. (1999). Social relationships across contexts: Family-Peer linkage. In W. A. Collins, \& B. Laursen (Eds.), Relationships as developmental contexts: The 30th Minnesota Symposium on Child Psychology (pp. 211-240). Hillsdale, NJ: Erlbaum.

Raikes, H. A., \& Thompson, R. A. (2005). Relationships past, present. And future: Reflections on attachment in middle childhood. In K.A. Kerns \& R.A. Richardson (Eds.), Attachment in middle childhood (pp 255-283), Guilford, N.Y.

Rydell, A. M., Hagekull, B., \& Bohlin, G. (1997). Measurement of two social competence aspects in middle childhood. Developmental Psychology, 33, 824-833. https://doi.org/10.1037/0012-1649.33.5.824

Saarni, C., Mumme, D., \& Campos, J. (1998). Emotional development: Action, communication, and understanding. In W. Damon (Series Ed.), \& N. Eisenberg (Vol. Ed.), Handbook of child psychology: Social and personality development (Vol. 3, pp. 238-309). New York: Wiley.

Scott, S., Briskman, J., Woolgar, M., Humayun, S., \& O'Connor, T.G. (2011). Attachment in adolescence: Overlap with parenting and unique prediction of behavioral adjustment. Journal of Child Psychology and Psychiatry, 52(10), 1052-1062. https://doi.org/10.1111/j.1469-7610.2011.02453.x

Schneider, B. H., Atkinson, L., \& Tardif, C. (2001). Child Parent attachment and children's peer relations: A quantitative review. Developmental Psychology, 37, 86-100. https://doi.org/10.1037/0012-1649.37.1.86

Solomon, J., \& George, C. (2008). The measurement of attachment security and related constructs in infancy and early childhood. In J. Cassidy \& P. R. Shaver (Eds.), Handbook of attachment: Theory, research, and clinical 
applications (pp. 383-416). New York: Guilford.

Solomon, J., George, C., \& De Jong A. (1995). Children classified as controlling at age six: Evidence of disorganized representational strategies and aggression at home and at school. Development and Psychopathology, 7, 447-463. https://doi.org/10.1017/S0954579400006623

Seibert, A., \& Kerns, K. (2015). Early mother-child attachment: Longitudinal prediction to the quality of peer relationships in middle childhood. International journal of Behavioral Development, 39(2) 130-138. https://doi.org/10.1177/0165025414542710

Van Ijzendoorn, M. H., Vereijken, C. M. J. L., Bakermans, K. M. J., \& Riksen, W. J. M. (2004). Assessing attachment security with the attachment Q Sort: Meta-analytic evidence for the validity of the observer AQS. Child Development, 75(4), 1188-1213. https://doi.org/10.1111/j.1467-8624.2004.00733.x

Verschueren, K., \& Koomen, H. M. Y. (2012). Teacher-child relationships from an attachment perspective. Attachment and Human Development, 14(3), 205-211. https://doi.org/10.1080/14616734.2012.672260

Waters, E., \& Cummings, E. M. (2000). A secure base from which to explore close relationships. Child Development, 71, 164-172. https://doi.org/10.1111/1467-8624.00130

Weinfield, N. S., Ogawa, J. R., \& Sroufe, L. A. (1997). Early attachment as a pathway to adolescent peer competence. Journal of Research on Adolescence, 7, 241-265. https://doi.org/10.1207/s15327795jra0703_1

Williams, S. K., \& Kelly, F. D. (2005). Relationships among involvement, attachment and behavioral problems in adolescence: Examining father's influence. The Journal of Early Adolescence, 25, 168-196. https://doi.org/10.1177/0272431604274178

Yair, G. (1991). The deprivation index: Paradoxes and empirical assessment, policy implications. Megamot, 34, 5-26. (In Hebrew).

\section{Copyrights}

Copyright for this article is retained by the author(s), with first publication rights granted to the journal.

This is an open-access article distributed under the terms and conditions of the Creative Commons Attribution license (http://creativecommons.org/licenses/by/4.0/). 